Original Research Article

\title{
Evaluation of propranolol, flunarizine and divalproex sodium in prophylaxis of migraine
}

\author{
Majid F. Bhat ${ }^{1}$, Harpreet S. Sidhu ${ }^{2 *}$, Manoj Goyal ${ }^{3}$
}

${ }^{1}$ Department of Pharmacology, Maharishi Markandeshwar Medical College \& Hospital, Kumarhatti, Solan 173229, India ${ }^{2}$ Department of Pharmacology, Maharishi Markandeshwar Institute of Medical Sciences and Research, Mullana, Ambala 133207, India

${ }^{3}$ Department of Pharmacology, N.C Medical College \& Hospital, Panipat, Haryana 132107, India

Received: 31 July 2017 Accepted: 28 August 2017

*Correspondence to: Dr. Harpreet S. Sidhu, Email: drharry5000@ hotmail.com

Copyright: (C) the author(s), publisher and licensee Medip Academy. This is an openaccess article distributed under the terms of the Creatve Commons Attribution NonCommercial License, which permits unrestricted noncommercial use, distribution, and reproduction in any medium, provided the original work is properly cited.

\begin{abstract}
Background: Preventive treatment has an important role in the management of migraine. Propranolol and flunarizine have been used for more than two decades while, open-label, controlled studies suggest divalproex sodium may also be efficacious for migraine prevention. The objective of the study to compare efficacy and safety of propranolol, flunarizine and divalproex sodium in patients for migraine prophylaxis.

Methods: Following approval from IEC a 12-week randomized, open, comparative study was carried out at the outpatient department of Medicine. Patients between 18 to 65 years, with history of 3 to 12 migraines a month (IHS) for six months were included. Patients were divided into three groups of 30 patients to receive - propranolol 20 to $160 \mathrm{mg} /$ day; flunarizine 5 to $10 \mathrm{mg} /$ day or divalproex sodium 250 to $750 \mathrm{mg} /$ day, for three months.

Results: Total 90/116 patients completed the study. No significant differences were found between the groups with regards to mean age or other baseline migraine features. All the drugs significantly decreased the frequency, duration and severity of migraine $(\mathrm{P}<0.001)$. There is no statistically significant difference between propranolol, flunarizine and divalproex sodium for any of the efficacy parameters. All the three treatments were well-tolerated and safe.

Conclusions: All the three study drugs were equally effective with an acceptable tolerability profile, Divalproex sodium group showed more side effects, none of which were serious. However, further studies with larger number of patients and longer duration of treatment are recommended.
\end{abstract}

Keywords: Divalproex sodium, Flunarizine, Migraine, Prophylaxis, Propranolol

\section{INTRODUCTION}

Migraine is one of the oldest, debilitating ailments known to man and is characterized by recurring, frequent, unilateral headaches lasting between 4 and 72 hours, aggravated by routine physical activity. It is often accompanied by a variety of symptoms which may be autonomic, neurological, and gastrointestinal in nature. Some of the symptoms associated with migraine are; nausea, vomiting, loss of appetite, photophobia, phonophobia, osmophobia. ${ }^{1-3}$

The discovery of migraine has been credited to Aretaeus of Cappadocia, who in second century described the nature 
of migraine pain and the vomiting associated with it. In 200 A.D, Galenus of Pergamon used the term "MIGRAINE" which is derived from a Latin word hemicrania, "hemi" meaning (half) and "crania" meaning (skull) to describe the unilateral pain in the head during an attack. In addition, he also pointed to a possible connection between brain and stomach due to the vomiting that seemed to be related to migraine. ${ }^{1-3}$

Migraine was ranked as the seventh-highest specific cause of disability and the third most prevalent disorder worldwide in Global Burden of Disease Survey 2010, with a prevalence of $6.5 \%$ in men and $18.2 \%$ in women. ${ }^{4-6}$ however, it still remains under-reported, under-diagnosed and under-treated. Highest prevalence is found in age groups 25 to 55 years. More than $70 \%$ of cases have family history of migraine..$^{6,7}$

The management of migraine involves nonpharmacological and pharmacological approaches and the choice of therapy depends on the severity of the attack. The non-pharmacological therapies include avoidance of trigger factors and lifestyle modifications, while as Pharmacotherapy for primary headache disorders is traditionally divided into acute and preventive therapies. ${ }^{8,9}$ The U.S. Headache Consortium and European Federation of Neurological Societies (EFNS) Task Force guidelines on the drug treatment of migraine have established the circumstances that might warrant preventive treatment. $^{10-12}$

A preventive drug should be chosen based on its proven efficacy, the patient's preferences and headache profile, the drug's side effects, and the presence of any coexisting disease. The updated 2012 guidelines from the American Academy of Neurology (AAN) and the American Headache Society (AHS) classify preventive agents on 4 levels: ${ }^{13-15}$

- Level A include drugs with established efficacy, for e.g.; beta-blockers, calcium channel blockers and antiepileptics

- Level B include drugs with probable efficacy, for e.g.; antidepressants, herbal remedies, vitamins and minerals.

- Level C consists of drugs that have probable efficacy for e.g.; candesartan, lisinopril cyproheptadine, and minerals such as co-enzyme Q-10 are included in this class

- Level U comprises of drugs with inadequate or conflicting data for prevention of migraine, for e.g.; clonazepam, clonidine, lamotrigine, nifedipine vigabatrin.

In light of the preliminary evidence suggesting effectiveness and the potential therapeutic advantages of these anti migraine agents, an attempt is made to evaluate the efficacy and safety of Propranolol, Flunarizine and Divalproex Sodium in migraine prophylaxis over a period of twelve weeks.

\section{METHODS}

One hundred and sixteen patients satisfying the International Headaches Society (IHS) criteria for migraine were included for the present prospective, randomized, comparative, open-label study in a tertiary care hospital. Written informed consent was obtained from all the patients after fully explaining the study procedure to their satisfaction.

\section{Inclusion criteria}

Patients of either sex, between the age of 18 to 55 years who fulfilled the migraine IHS criteria, had 2 to 5 migraine headaches (periods) and no more than 15 headache days (including migraine days) to avoid tension type headache/ status migrainous, Women were required to be postmenopausal, surgically incapable of bearing children or having a medically acceptable method of birth control for at least 1 month before study entry. Women of reproductive age were screened through Urine Pregnancy Test (UPT) and Patients who were willing to give voluntary written informed consent to participate in the study were included in the study.

\section{Exclusion criteria}

Patients having age less than 18 years or more than 55 years, non co-operative / not willing to sign the consent, pregnant or lactating women, patients with acute emergencies or with impaired renal or hepatic function, patients having history of hypersensitivity / allergy to any of the drugs included in study, or with history of any systemic illness, and any other limitations to the use of $\beta$ blockers, calcium channel blockers and anti-epileptics were excluded from the study.

A detailed history taking and relevant investigations were done to confirm the diagnosis and to detect any underlying complications associated with migraine. Data was collected using a specially designed Performa, which was filled by a personal interview with each patient. For baseline, the average number, duration and severity of attacks per month for the past 3 months before the start of the study was obtained. All patients were issued a migraine diary which will had a incorporated visual analogue scale (VAS) and were explained how to record the number, duration of attacks and severity of migraine headaches according to the visual analogue scale (VAS). To assess the grade of disability caused by migraine, each patient was administered with a five-item Migraine Disability Assessment Score (MIDAS) questionnaire at the start and at the end of the treatment period.

\section{Treatment}

The selected patients who satisfied the diagnostic criteria for migraine and who met the inclusion criteria were enrolled into the study and were randomized by a computer-generated randomization schedule to receive 
either of the following drugs in recommended doses given below: Propranolol (PROP) 40mg up to $160 \mathrm{mg} /$ day, FLUNARIZINE (FLU) $5 \mathrm{mg}$ up to $10 \mathrm{mg} / \mathrm{day}$, DIVALPROEX SODIUM (DVP) $250 \mathrm{mg}$ to be increased up to $500 \mathrm{mg} /$ day based on patient's response. All the patients received drug by study investigator who also ensured that the adequate instructions have been given to the patients regarding the medication. Thereafter, patients were asked to come for follow-up regularly at the end of 1st, 2rd and 3th month respectively. All patients were reminded of the follow-up through telephonic interview. During each visit, the patients were asked for any symptoms of drowsiness or any other common adverse drug effects they felt or noticed also parameters like; Respiratory rate, weight, pulse rate, blood pressure (supine and standing) were noted. Treatment-emergent adverse effects were recorded on the Adverse Effect Page of the Case Report Form. Patients were allowed to use concomitant rescue medication to abort migraine attacks.

\section{Statistical analysis}

Data collected was entered in Microsoft office excel version 2007 and analysed by Statistical Package for the Social Sciences (SPSS) computer program for windows version 20 by IBM, Chicago. Categorical data was expressed as No. (\%age) and was analysed by chi-square test to test the significance of association between the variables. Continuous data was expressed as Mean \pm Standard Deviation (SD) and statistical significance was determined by Analysis of Variance (ANOVA) / Kruskal Wallis test depending upon the normality distribution of data. Post-hoc Tukey's test has been employed to test the significance of Inter group comparison of the three groups. $\mathrm{P}$ value $\leq 0.05$ is considered Significant and $\mathrm{P} \leq 0.001$ is considered highly Significant.

\section{RESULTS}

\section{Patient demographics and baseline characteristics}

In the present study, of the total 116 patients enrolled and randomized (PROP=37, FLU=39and DVP=40), 26 withdrew during different stages of the study. The rest ninety subjects complete the study and were included in the analysis. Actual numbers and the reasons for withdrawal of patients are depicted in Figure 1. Out of a total of 90 patients, $40(44.4 \%)$ patients were in the $26-35$ years age group (Figure 2). The total number of males and females were $37(41 \%)$ and $53(59 \%)$ respectively (Figure 3 ). There were no significant differences in age of patients of three groups $(\mathrm{P}=0.214)$ and in the gender distribution $(p=0.955)$. At baseline, there were no other significant differences between treatment groups in demographics or baseline characteristics (Table 1).

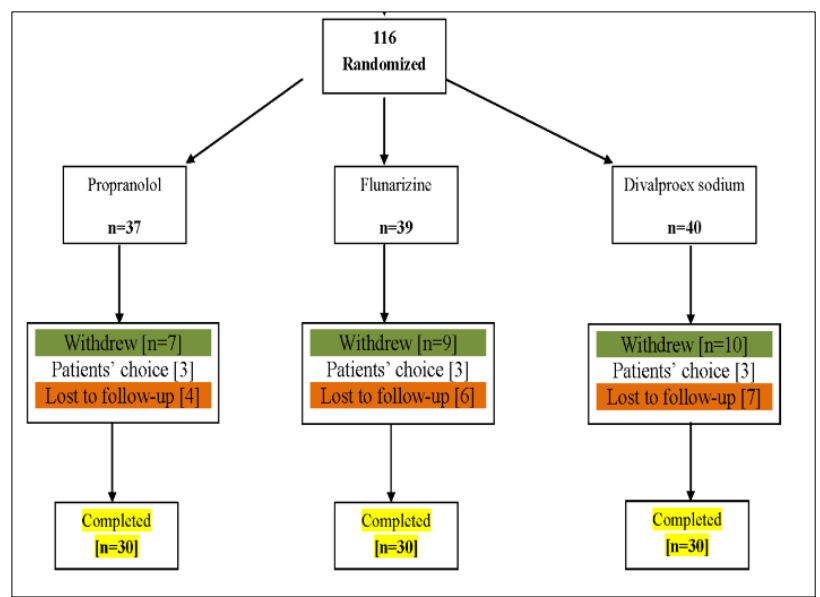

Figure 1: Patient disposition during the study.

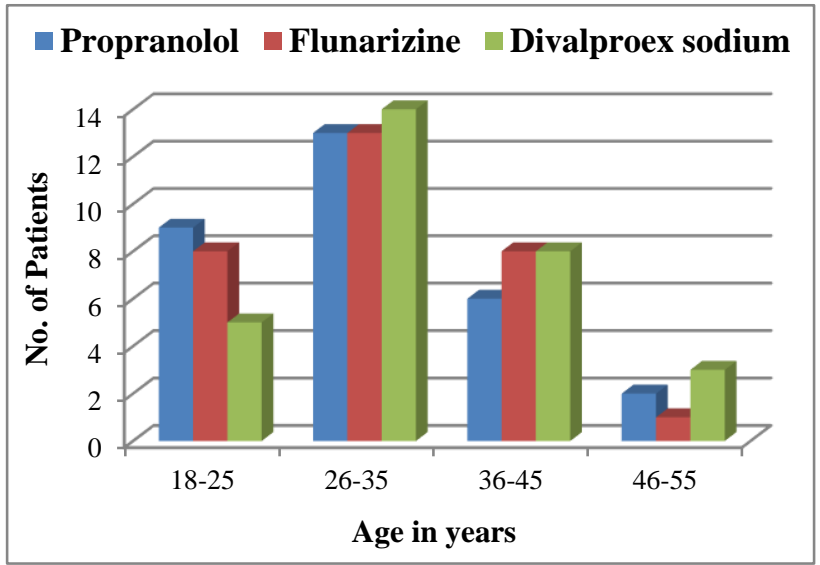

Figure 2: Age wise distribution of patients in the three study groups.

Table 1: Age wise distribution of patients.

\begin{tabular}{|llllllll|}
\hline & \multicolumn{2}{l}{ Propranolol } & \multicolumn{2}{l}{ Flunarizine } & \multicolumn{2}{c|}{ Divalproex sodium } \\
& Mean & SD & Mean & SD & Mean & SD & p value \\
\hline Age & 31.3 & 7.9 & 31.2 & 7.5 & 34.5 & 9.0 & 0.214 \\
\hline Frequency/Month. & 5.07 & 1.44 & 5.47 & 1.43 & 5.4 & 1.98 & 0.599 \\
\hline Average Duration & 20.67 & 6.22 & 20.73 & 6.07 & 18.43 & 7.55 & 0.317 \\
\hline VAS & 7.2 & 1.69 & 6.7 & 1.78 & 7.1 & 2.09 & 0.548 \\
\hline MIDAS & 11.57 & 4.17 & 11.37 & 4.48 & 10.73 & 3.79 & 0.721 \\
\hline Weight & 59.97 & 12.88 & 64.9 & 10.84 & 67.47 & 13.95 & 0.070 \\
\hline
\end{tabular}

The difference between the treatment groups was not significant in any of the above parameters. VAS-Visual Analogue Scale, MIDASMigraine Disability Assessment Score 
Table 2: Summary of the treatment outcome at the end of the study period.

\begin{tabular}{|llllllll|}
\hline & $\begin{array}{l}\text { Propranolol } \\
\text { change in } \\
\text { score from } \\
\text { baseline } \\
\text { (mean } \pm \text { SD) }\end{array}$ & $\begin{array}{l}\text { P value } \\
\text { from } \\
\text { baseline }\end{array}$ & $\begin{array}{l}\text { Flunarizine } \\
\text { change in } \\
\text { score from } \\
\text { baseline } \\
\text { (mean } \pm \text { SD) }\end{array}$ & $\begin{array}{l}\text { P value } \\
\text { from } \\
\text { baseline }\end{array}$ & $\begin{array}{l}\text { Divalproex } \\
\text { sodium } \\
\text { change in score } \\
\text { from baseline } \\
\text { (mean } \pm \text { SD) }\end{array}$ & $\begin{array}{l}\text { P value } \\
\text { from } \\
\text { baseline }\end{array}$ & $\begin{array}{l}\text { Inter- } \\
\text { group } \\
\text { difference }\end{array}$ \\
\hline Frequency/Month & $-4.7 \pm 1.39$ & $<0.001 * *$ & $-5.1 \pm 1.67$ & $<0.001 * *$ & $-4.93 \pm 1.87$ & $<0.001^{* *}$ & 0.645 \\
\hline Average Duration & $-19.8 \pm 6.53$ & $<0.001 * *$ & $-19.97 \pm 6.31$ & $<0.001 * *$ & $-17.23 \pm 7.75$ & $<0.001^{* *}$ & 0.232 \\
\hline VAS & $-6.63 \pm 1.97$ & $<0.001 * *$ & $-6.20 \pm 2.31$ & $<0.001 * *$ & $-6.50 \pm 2.39$ & $<0.001^{* *}$ & 0.744 \\
\hline MIDAS & $-3.77 \pm 3.29$ & $<0.001 * *$ & $-3.13 \pm 2.67$ & $<0.001 * *$ & $-3.10 \pm 2.35$ & $<0.001^{* *}$ & 0.766 \\
\hline Weight Gain & $0.2 \pm 0.48$ & $0.031^{*}$ & $0.47 \pm 1.01$ & $0.017^{*}$ & $0.9 \pm 1.16$ & $<0.001^{* *}$ & $0.016^{*}$ \\
\hline
\end{tabular}

** denotes highly significant $\mathrm{P}$ value $(\mathrm{P}<0.001)$, *denotes significant $\mathrm{P}$ value $(\mathrm{P}<0.05)$

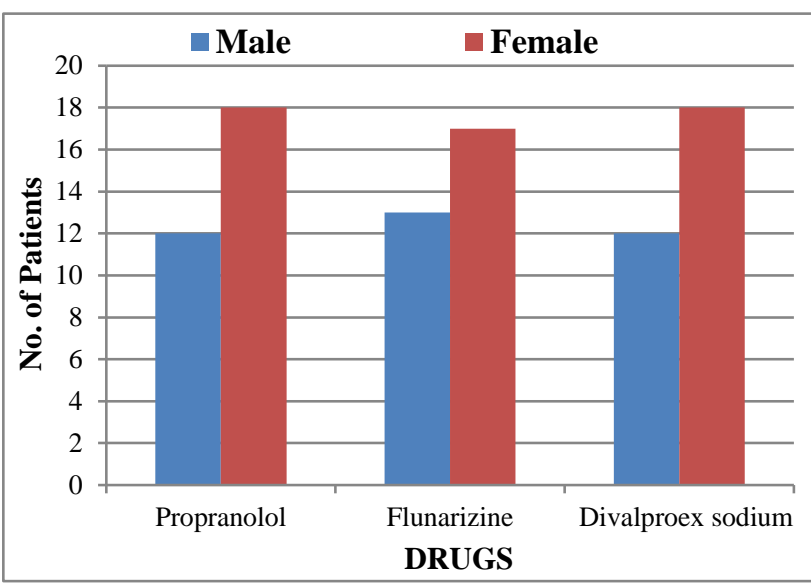

Figure 3: Gender wise distribution of patients in the three study groups.

\section{Efficacy measures}

Frequency of migraine attacks per month

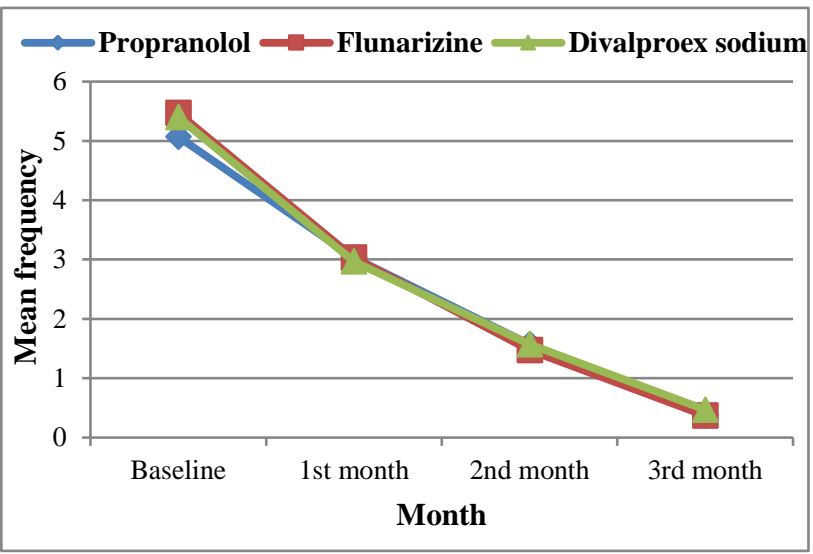

Figure 4: Change in monthly migraine frequency in the three study groups.

Overall, all the three drug treatments resulted in a progressive and statistically significant $(\mathrm{P}<0.001)$ reductions in the mean migraine frequency, significant difference was reached as early as the 1st month for the all the three groups and remained statistically significant throughout the treatment phase (Figure 4). The maximum change from baseline to final reading was for the FLU group $(5.1 \pm 1.67)$ but was not statistically significant $(\mathrm{P}=0.645)$ when compared with PROP (4.7 \pm 1.39$)$ and DVP (4.93 \pm 1.87 ) (Table 2).

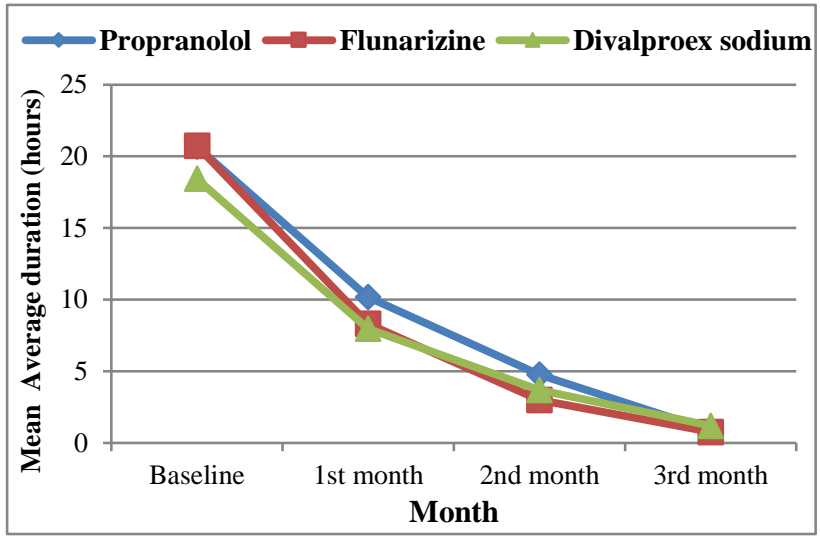

Figure 5: Change in Average duration (hours) of migraine over time in the three study groups.

Average duration of migraine

There was a progressive and statistically significant $(\mathrm{P}<0.001)$ decrease in the average duration of the migraine attacks in all the three treatment groups, significant reduction was seen as early as the 1st month for the all the three groups and remained statistically significant throughout the treatment phase (Figure 5). Though the maximum change from baseline to final reading was for the FLU group $(19.97 \pm 6.31)$ but was not statistically significant $(\mathrm{P}=0.232)$ when compared with PROP (19.8 \pm 6.53$)$ and DVP (17.23 \pm 7.75$)$ (Table 2).

\section{Headache severity}

The mean migraine intensity on VAS was significantly reduced $(\mathrm{P}<0.001)$ in all the three groups and was seen as early as the 1 st month for the all the three groups and 
remained statistically significant throughout the treatment phase (Figure 6). Maximum change in severity of migraine was seen with PROP $(6.63 \pm 1.97)$ followed by DVP $(6.50 \pm 2.39)$ and FLU $(6.20 \pm 2.31)$ but there was no significant difference between the three drugs when compared to each other $(\mathrm{P}=0.744)$ (Table 2).

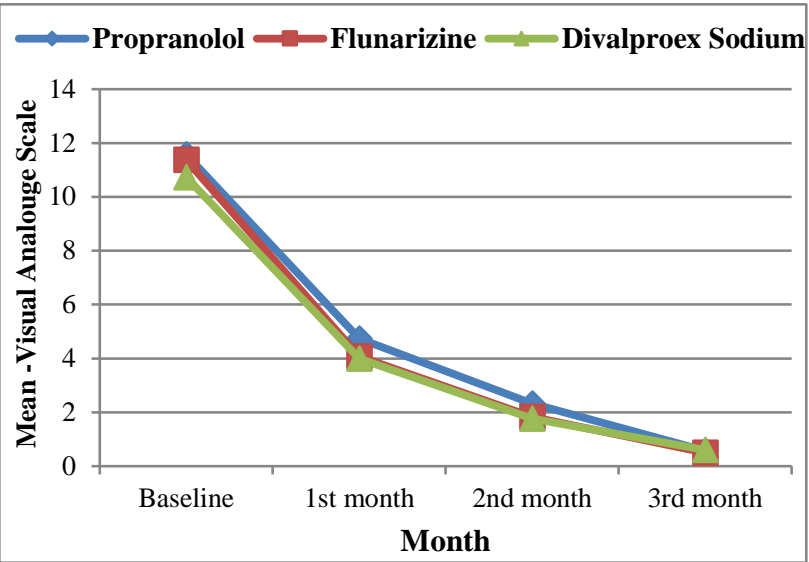

Figure 6: Change in severity of monthly migraine attacks using VAS score in the three study groups.

\section{Migraine disability assessment}

The difference in the mean MIDAS scores in all treatment groups was found to be insignificant at the baseline $(\mathrm{P}=0.721)$ (Table 1). However, a significant reduction in MIDAS scores was noted at the end of treatment period when compared to the baseline $(\mathrm{P}<0.001)$ (Table 2, Figure $7)$ in all the treatment groups. The intergroup differences were not significant $(\mathrm{P}=0.766)]$ (Table 2).

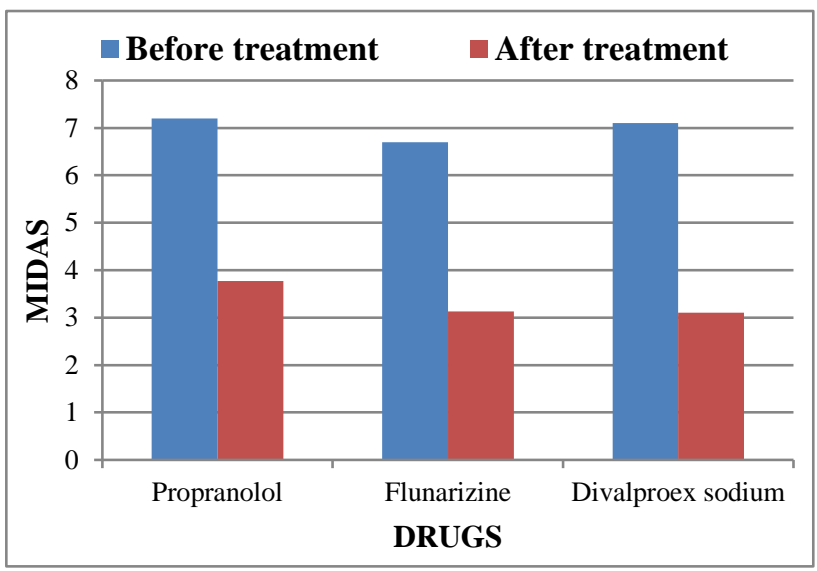

Figure 7: Change in MIDAS score in the three study groups before and after treatment.

\section{Safety and tolerability}

The Adverse Drug Reactions observed in our study were generally mild in nature, well tolerated by the patients and did not lead to discontinuation of the treatment. Also, there were no serious side effects observed during the course of study. Adverse effects were reported in 39 patients. The occurrence of adverse drug reaction was found to be high in DVP group followed by FLU group and PROP. Most common adverse events were weight gain and tiredness, seen in 24 and 5 patients respectively. 5 patients from PROP group, 6 patients from FLU group and 13 patients from DVP group experienced significant weight gain at the end of the treatment period, $(\mathrm{P}=0.0321, \mathrm{P}=0.017$ and $\mathrm{P}<0.001$ respectively). Maximum weight gain was seen with DVP $(0.9 \pm 1.16)$ followed by FLU $(0.47 \pm 1.01)$ and PROP $(0.2 \pm 0.48)$, there was significant difference between the three drugs when compared to each other $(\mathrm{P}=0.016)$ (Table 2). Other side effects observed in the PROP group were somnolence, tiredness and dizziness. Tiredness, insomnia and facial swelling in FLN group, and tremors, hair loss and nausea in DVP group (Figure 8).

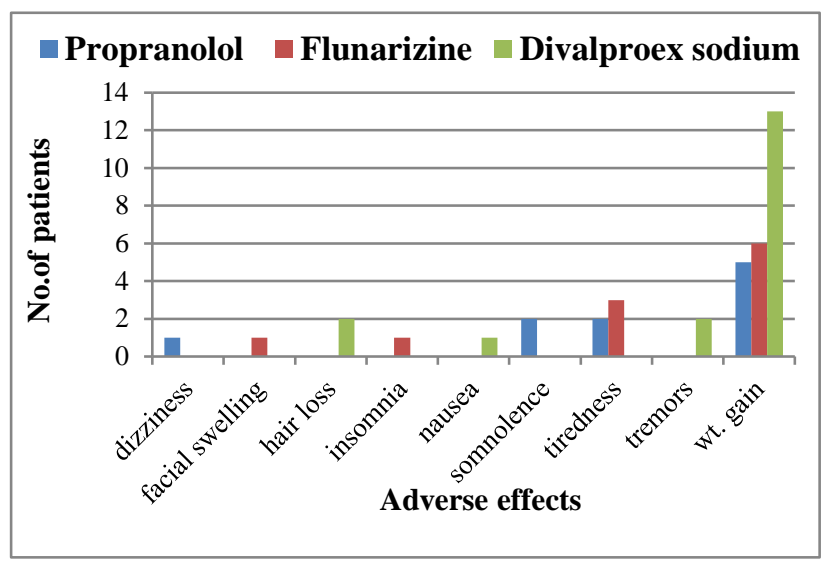

Figure 8: Distribution of patients according to adverse effects in the three study groups.

\section{DISCUSSION}

The present study was conducted to compare efficacy and safety of PROP, FLU and DVP in migraine prophylaxis among patients reporting at Maharishi Markandeshwar Institute of Medical Science and Research (MMIMSR). An open label experience from medicine O.P.D. at MMIMSR has demonstrated the use of all the three drugs as agents in prophylaxis of migraine but the comparative clinical study between them is lacking which prompted us to carry out the present study.

In the present study, the demographic data revealed 26 to 35 years as the most common age group suffering from migraine. Almost $44 \%$ patients belonged to this group. Study by Russell et al reports that the second and third decade of life as the most common age of onset of migraine. ${ }^{16}$ Out of 90 patients, $53(58.88 \%)$ were females and $37(41.12 \%)$ were males, overall incidence of migraine was found to be higher in females ratio being 1.5:1 which is the ratio found in most of the studies. ${ }^{17}$ The reason for the preponderance in women is still unexplained. Though female sex steroids do not seem to be involved in the pathogenesis of migraine per se, they may modulate several mediators and/or receptor systems via both genomic and non-genomic mechanisms; these actions may 
be perpetuated at the central nervous system, as well as at the peripheral (neuro) vascular level.

All the three drugs PROP, FLU and DVP have shown a high degree of effectiveness and a slight advantage of FLU in reducing the frequency and duration of migraine, while as PROP was more effective in reducing the severity of attacks, but none among these has reached the level of statistical significance. A systematic review by Linde $\mathrm{K}$ and Rossnagel K, Propranolol was found to be more effective than placebo and no clear differences were found between propranolol and other migraine-preventing drugs like; amitriptyline, flunarizine, cyclandelate, etc. ${ }^{18}$ Another study by Linde $\mathrm{M}$ et al, in 2013, reported no significant difference in the proportion of responders between divalproex sodium versus propranolol or between sodium valproate versus flunarizine for preventing migraine attacks in adult patients with episodic migraine. ${ }^{19}$ Other studies and meta-analysis have also reported similar results. ${ }^{20,21}$

In PROP group, five patients showed weight gain, two patients showed somnolence and tiredness. In FLN group, six patients showed Weight gain, three patients complained of tiredness and insomnia and facial swelling were seen in one patient each. In DVP group, thirteen patients showed weight gain, two patients had tremors and two patients complained of hair loss. Number of patients experiencing weight gain in DVP group was significantly high when compared to PROP and FLU. Maximum weight gain was seen with DVP followed by FLU and PROP, there was significant difference between the three drugs when compared to each other. A study by Taylor FR concludes that migraine preventive medications have been associated with weight gain, a higher incidence of weight gain was observed divalproex sodium than with propranolol and flunarizine. ${ }^{22}$ These findings are coinciding with the result of various studies comparing the efficacy and safety of drugs in prophylaxis of migraine. ${ }^{14,21}$ Most of the patients recovered from the ADRs despite without any intervention.

\section{CONCLUSION}

The results of this study demonstrate that prophylactic treatment with either of the three drugs PROP, FLU and DVP to be equally effective in reducing the frequency of migraine, duration and severity of migraine headaches at the end of 3 months of treatment. The disability caused by migraine headaches was also reduced by all the three drugs when compared to the baseline. No significant difference was observed among the three groups with respect to the migraine characteristics. All the treatment drugs were well-tolerated and safe, but more side effects were seen with divalproex sodium, but none of which was serious. Significant weight gain was seen in divalproex sodium treated patients at the end of study. Overall the three treatment drugs are equally efficacious but they have different adverse effects and contraindications in different patients and thus individualization of drug therapy should be considered corresponding to the patient profile. The current study demonstrated the comparison of three drugs in migraine prophylaxis.

\section{Limitations}

This study has several limitations. The number of patients who completed the study in three groups was too small, so that the conclusions on the effectiveness of these treatments must be interpreted very cautiously. Future studies evaluating the efficacy of drugs for the prophylaxis migraine should include a larger number of patients. Another limitation is that the Rescue medications were not registered in the pre treatment and treatment phases. However, despite these limitations, this study points to some data that should be taken into account in future studies.

\section{Funding: No funding sources Conflict of interest: None declared \\ Ethical approval: The study was approved by the Institutional Ethics Committee (IEC/MMIMSR/16/225)}

\section{REFERENCES}

1. Critchley M. Migraine: From Cappadocia to Queen Square. Background to Migraine In: Smith R, ed. London: Heinemann. 1967;1:28-39.

2. Mathew NT. Migraine. In: Evans RW, Mathew NT. Handbook of Headache. Second Edition. Lippincott Williams \& Wilkins; 2005:28-55.

3. Silberstein SD. Preventive migraine treatment. Neurol Clin. 2009;27(2):429-43.

4. Headache Classification Committee of the International Headache Society (IHS). The International Classification of Headache Disorders, $3^{\text {rd }}$ Edition (beta version). Cephalgia. 2013;33:629-808.

5. Wang SJ, Chung CS, Chankrachang S, Ravishankar K, Merican JS, Salazaret G. Migraine disability awareness campaign in Asia: migraine assessment for prophylaxis. Headache. 2008;48;1356-65.

6. Silberstein SD. In: Taylor \& Francis eds. Headache in clinical practice, $2^{\text {nd }} \mathrm{Ed} ; 2002$.

7. Migraine RK. The New Understanding. Supplement of JAPI. Apr. 2010;58:30-3.

8. Deleu D, Hanssens Y. Guidelines for the prevention of migraine. Neurosciences. 2000;5(1):7-12.

9. DeeAmico D, Stewart JT, Prophylaxis of migraine: General principles and patient acceptance. Neuropsychiatric Disease and Treatment. 2008;4(6):1155-67.

10. Silberstein SD. US Headache Consortium Practice parameter: evidence based guidelines for migraine headache (an evidence-based review): report of the Quality Standards Subcommittee of the American Academy of Neurology. Neurology. 2000;55:754-62.

11. Evers S. European Federation of Neurological Societies. EFNS guideline on the drug treatment of migraine-revised report of an EFNS task force. Eur $\mathbf{J}$ Neurol. 2009;16:968-81. 
12. Lipton RB, Bigal ME, Diamond M, Freitag F. AMPP Advisory Group. Migraine prevalence, disease burden, and the need for preventive therapy. Neurology. 2007;68(5):343-9.

13. Vongvaivanich K. Update on Migraine Prophylaxis: Things that can help your migraine patients. The Bangkok Medical Journal. 2013 Feb;5:50-60.

14. Ecsei LV, Majlath Z, Szok D, Csati A, Tajti J. Drug safety and tolerability in prophylactic migraine treatment. Expert Opin. Drug Saf. 2015;14(5):1-15.

15. Weatherall MW. Drug therapy in headache. Clinical Medicine. 2015;15(3):273-9.

16. Russell MB, Rasmussen BK, Brennum J. Presentation of a new instrument: the diagnostic headache diary. Cephalalgia. 1992;12:369-74.

17. Leonardi M, Steiner TJ, Scher AT, Lipton RB. The global burden of migraine: measuring disability in headache disorders with WHO Classification of Functioning, Disability and Health (ICF). J. Headache Pain. 2005;6(6):429-40.

18. Linde K, Rossnagel K. Propranolol for migraine prophy- laxis. Cochrane Database Syst Rev. 2004;CD003225.
19. Linde M, Mulleners WM, Chronicle EP, McCrory DC. Valproate (valproic acid or sodium valproate or a combination of the two) for the prophylaxis of episodic migraine in adults. Cochrane Database of Systematic Reviews. 2013;6:CD010611.

20. Bostani A, Rajabi A, Moradian N. The effects of cinnarizine versus sodium valproate in migraine prophylaxis. Int J Neurosci. 2013;123(7):487-93.

21. Jackson JL, Cogbill E, Santana-Davila R, Eldredge C, Collier W, Gradall A, et al. A comparative effectiveness meta-analysis of drugs for the prophylaxis of migraine headache. PloS one. $2015 \mathrm{Jul}$ 14;10(7):e0130733.

22. Taylor FR. Weight change associated with the use of migraine preventive medications. Clinical therapeutics. 2008 Jun 30;30(6):1069-80.

Cite this article as: Bhat MF, Sidhu HS, Goyal M. Evaluation of propranolol, flunarizine and divalproex sodium in prophylaxis of migraine. Int J Basic Clin Pharmacol 2017;6:2463-9. 